Structures and Buildings Volume 169 Issue SB7

Maximum loads on shores during the construction of buildings

Buitrago, Adam, Alvarado, Calderón and

Gasch proceedings
Proceedings of the Institution of Civil Engineers Structures and Buildings 169 July 2016 Issue SB7 Pages 538-545 http://dx.doi.org/10.1680/jstbu.15.00089 Paper 1500089 Received 26/08/2015 Published online 20/01/2016 Accepted 02/12/2015 Keywords: concrete structures/design methods \& aids/ structures \& design ICE Publishing: All rights reserved
I

\title{
Maximum loads on shores during the construction of buildings
}

\section{Manuel Buitrago MEng}

PhD Candidate, ICITECH, Universitat Politècnica de València, Valencia, Spain

José M. Adam PhD

Senior Lecturer, ICITECH, Universitat Politècnica de València, Valencia, Spain (corresponding author: joadmar@upv.es)

\author{
Yezid A. Alvarado PhD \\ Lecturer, Pontificia Universidad Javeriana, Bogotá, Colombia \\ Pedro A. Calderón PhD \\ Professor, ICITECH, Universitat Politècnica de València, Valencia, Spain \\ Isabel Gasch PhD \\ Lecturer, ICITECH, Universitat Politècnica de València, Valencia, Spain
}

This paper describes a simplified method of estimating maximum loads on shores during the construction of multistorey buildings with in situ casting. Calculating this maximum value is fundamental to establish the design load of the shores and thus avoid possible safety problems caused by selecting the wrong type of shore. The procedure was verified and showed a good fit with both the experimental measurements and finite-element method calculations. This simplified procedure will be useful to both researchers and practitioners, who have to deal with this problem in the course of their daily work. The proposal also represents an important technology transfer to the industry as it is in the form of a simplified tool that comes fairly close to the results obtained by complex calculation methods. Actually, the maximum load obtained from the simplified method is $20.72 \mathrm{kN}$, which is very close to the value $21.37 \mathrm{kN}$ obtained from an advanced finite-element model.

\author{
Notation \\ E elasticity modulus of slab concrete \\ I moment of inertia \\ $k_{j, \max } \quad$ maximum deformation of slab $j$ under unitary load \\ (vertical displacement) \\ $k_{\mathrm{sh}, j \text {, max }}$ maximum deformation of shores on level $j$ under \\ unitary load (vertical displacement) \\ $L \quad$ inter-column distance \\ $M_{i} \quad$ negative bending moments in the strip supports \\ $Q \quad$ self-weight of slab \\ $Q_{j} \quad$ increased load on slabs on level $j$ \\ $Q_{j, \max } \quad$ increased maximum load on slabs on level $j$ \\ $q \quad$ load fraction assigned to strip \\ $S_{j} \quad$ increased load on shores on level $j$ \\ $S_{j, \max } \quad$ increased maximum load on shores on level $j$ \\ $S_{\text {max, Exp }}$ maximum load on shores measured \\ experimentally \\ $S_{\text {max, FEM }}$ maximum load on shores according to \\ finite-element method calculations \\ $S_{\text {max, NSP }}$ maximum load on shores according to proposed \\ procedure \\ $x_{\mathrm{m}} \quad$ position of maximum deformation of the strip \\ $\alpha \quad$ load ratios between two consecutive floors \\ $\Delta_{j, \max } \quad$ maximum deformation of slab $j$ (vertical \\ displacement) \\ $\Delta_{\text {max s }} \quad$ maximum deformation of column strips, $S_{\mathrm{c}}$; and \\ middle strips, $S_{\mathrm{m}}$ (vertical displacement)
}

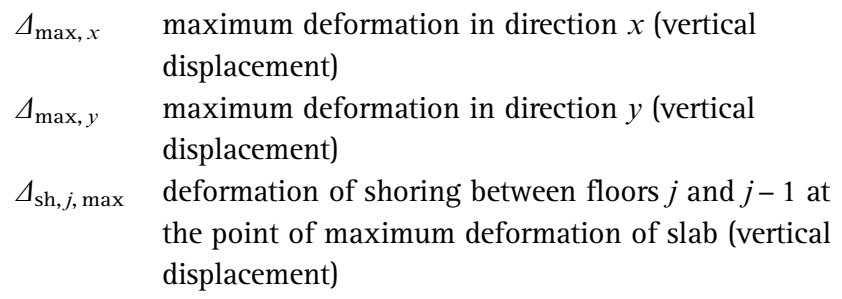

\section{Introduction}

The three aspects with the biggest influence on the construction of a building are construction time, financial cost and safety. This implies that in order to reach the required safety level and consider time and cost reductions, it is essential to know how loads are transmitted between slabs and shores during the construction process. In this way it can be determined whether or not slabs and shores are able to bear the loads applied to them. The importance of this aspect cannot be over-emphasised, as many building collapses occur in the course of the construction process (Epaarachchi et al., 2002; Kaminetzky, 1991; Kaminetzky and Stivaros, 1994).

To estimate load transmission between slabs and shores different research groups have come up with simplified calculation methods to reduce the degree of complexity without the need to use advanced software. Among others, Grundy and Kabaila (1963), Duan and Chen (1995), Fang et al. (2001) and 
Calderón et al. (2011) have proposed simplified methods of calculating slab/shore load transmission in multistorey buildings. The simplified method recently proposed by Calderón et al. (2011) improved upon the previous methods (Calderón et al., 2011; Gasch, 2012; Gasch et al., 2013, 2014) and adopted two new hypotheses: (a) mean slab deformation is considered to coincide with the mean deformation of the shores that support them, and $(b)$ different boundary conditions (internal, end and corner spans) are considered while deformability is estimated by the method of Scanlon and Murray (1982).

The simplified methods proposed to date analyse load transmission by establishing a global equilibrium between the slabs and shores. In this global analysis the actual distribution of the loads on the individual floors is not taken into account. Therefore, in order to obtain a representative value of the load assumed by each slab and shoring system, the analysis performed by the existing simplified methods is done using mean loads. In this way, applying the latest simplified method (Calderón et al., 2011), the mean loads on slabs and shores can be precisely calculated and it can be seen whether or not the slabs are able to withstand these loads. However, the shoring system must be designed for the expected maximum load, since, as has been proven both experimentally and numerically by Alvarado (2009), the loads on the shores of a single floor vary according to the position of the shore, and it is important to know this value in order to avoid safety problems when designing the shoring system and choosing the appropriate type of shore.

The aim of this study was to use a simplified method to estimate the maximum loads on shores during the construction of buildings with in situ casting to facilitate the calculations and avoid safety problems when selecting the type of shore to be used. The method's principal novelty resides in its proposal for calculating maximum load on shores based on the simplified method of Calderón et al. (2011). Furthermore, the new method represents an important transfer of technology to the building industry, as it is highly useful to both researchers and practitioners to be able to estimate the maximum load in a simple way without the need for specialised software.

\section{Simplified maximum load calculation method}

\subsection{Formulation}

Mean loads can be estimated in both slabs and shores by the simplified method of Calderón et al. (2011). The aim of the present study was to modify this method appropriately to obtain the expected maximum load on shores in each construction stage, so as to be able to estimate maximum load and, in turn, mean load, as proposed by Calderón et al. (2011). This method can be used to simulate casting, clearing, reshoring or striking (see Figure 1).
When a new slab is cast, the new load $(Q)$ causes increased loads on shores $\left(S_{j}\right)$ and slabs $\left(Q_{j}\right)$ according to the following expressions (see also Figure 1)

1. $S_{1}=Q_{1}$

2. $S_{2}=Q_{1}+Q_{2}$

3. $S_{j}=Q_{1}+Q_{2}+\cdots+Q_{j}$

4. $S_{n}=Q_{1}+Q_{2}+Q_{3}+\cdots+Q_{n}$

However, instead of assuming that mean slab deformation coincides with the mean deformation of its supporting shores (Calderón et al., 2011), the authors of the present work modified this hypothesis and considered that the maximum slab deformation coincided with shore deformation at the point of maximum deformation, thus assuming that the shore supporting the highest load would be at the point of maximum slab deformation, and therefore the objective was to carry out the study at this point. In this way, the equation of compatibility of displacements of two consecutive floors $j$ and $j-1$ is

5. $\Delta_{j, \max }=\Delta_{j-1, \max }+\Delta_{\mathrm{sh}, j, \max }$

where $\Delta_{j, \max }$ and $\Delta_{j-1, \max }$ are the maximum deformation of slabs $j$ and $j-1$, respectively, and $\Delta_{\mathrm{sh}, j, \max }$ is the deformation of the shoring between slabs $j$ and $j-1$ at the point of maximum deformation. Transforming these deformations into loads and expressing the load on shores according to Equations 1-4, the following expression is obtained

$k_{j, \max } \cdot Q_{j, \max }=k_{j-1, \max } Q_{j-1, \max }$
$+k_{\mathrm{sh}, j, \max }\left(Q_{1, \max }+Q_{2, \max }+\cdots+Q_{j, \max }\right)$

where the $k$ factors are the maximum deformations under a unitary load for both slabs and shores. To calculate factor $k$ in shores $\left(k_{\mathrm{sh}, j, \mathrm{max}}\right)$ the same expression is used as in Calderón et al. (2011). The calculation of factor $k$ in shores $\left(k_{j, \max }\right)$ is described in detail in the following section.

From this point on, the load ratios on the slabs between two consecutive shored floors can be calculated from Equation 6

7. $\quad \alpha_{21}=\frac{Q_{2, \max }}{Q_{1, \max }}=\frac{k_{1, \max }}{k_{2, \max }}+\frac{k_{\mathrm{sh}, 2, \max }}{k_{2, \max }}$ 


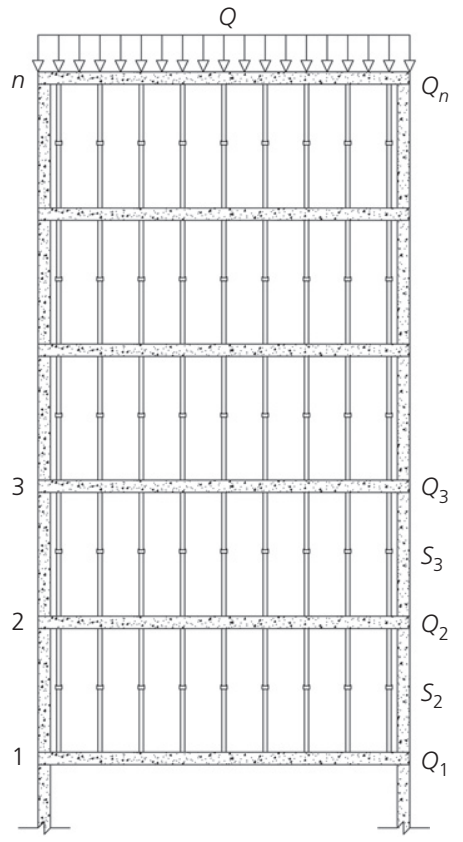

(a)

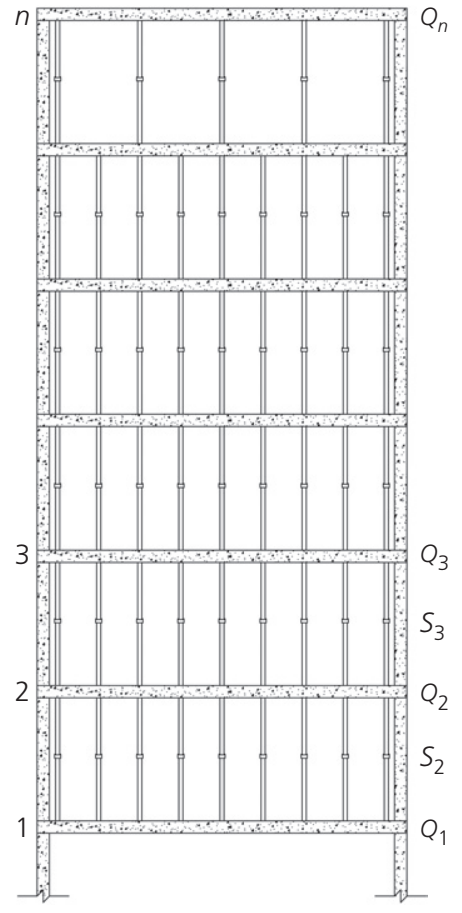

(b)

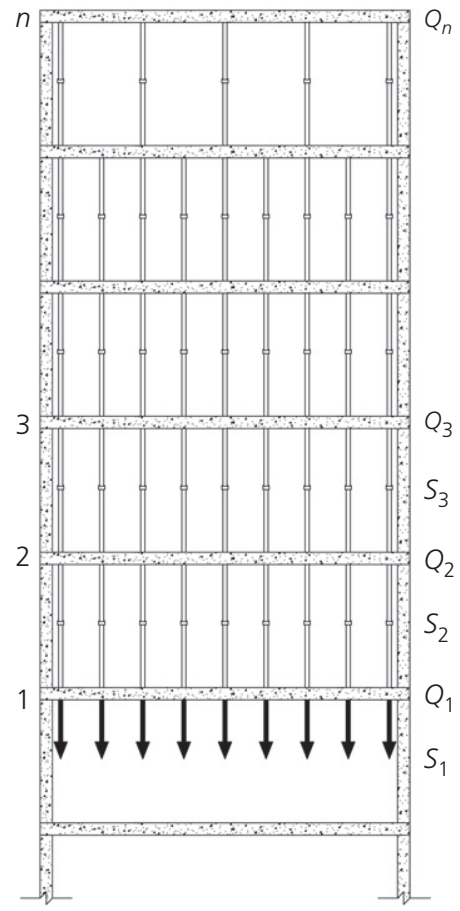

(c)

Figure 1. Operations of (a) casting of final slab, (b) clearing or reshoring of final slab and (c) striking of first slab

8. $\quad \alpha_{32}=\frac{Q_{3, \max }}{Q_{2, \max }}=\frac{k_{2, \max }}{k_{3, \max }}+\frac{k_{\mathrm{sh}, 3, \max }}{k_{3, \max }}\left(1+\frac{1}{\alpha_{21}}\right)$

9. $\quad \alpha_{43}=\frac{Q_{4, \max }}{Q_{3, \max }}=\frac{k_{3, \max }}{k_{4, \max }}+\frac{k_{\mathrm{sh}, 4, \max }}{k_{4, \max }}\left(1+\frac{1}{\alpha_{32}}+\frac{1}{\alpha_{21} \alpha_{32}}\right)$

10.

$$
\begin{aligned}
\alpha_{n n-1}= & \frac{Q_{n, \max }}{Q_{n-1, \max }}=\frac{k_{n-1, \max }}{k_{n, \max }} \\
& +\frac{k_{\mathrm{sh}, n, \max }}{k_{n, \max }}\left(1+\frac{1}{\alpha_{n-1 n-2}}+\frac{1}{\alpha_{n-1 n-2} \alpha_{n-2 n-3}}+\cdots\right)
\end{aligned}
$$

The increased load of a new casting, clearing and reshoring is distributed among the lower floors by way of the shoring, so that the following expression can be established

11. $\sum_{j=1}^{n} Q_{j, \max }=Q$
Finally, using the expressions obtained, the increased loads on slabs caused by casting, clearing and reshoring can be calculated in accordance with the following expressions

12. $Q_{1, \max }=\frac{Q}{1+\alpha_{21}+\alpha_{21} \alpha_{32}+\alpha_{21} \alpha_{32} \alpha_{43}+\cdots}$

As Calderón et al. (2011) have pointed out, the striking operation is equivalent to applying a downward force of the same magnitude as the forces supported by the removed shores (see Figure 1(c)), bearing in mind that in this case the load transmission is reversed.

\subsection{Maximum slab deformation under unitary load} The factor $k_{j, \max }$ is defined as the maximum deformation of slabs under unitary load. Slab deformation can be estimated by different methods; however, for the boundary conditions considered (internal, end and corner spans), and as it was 

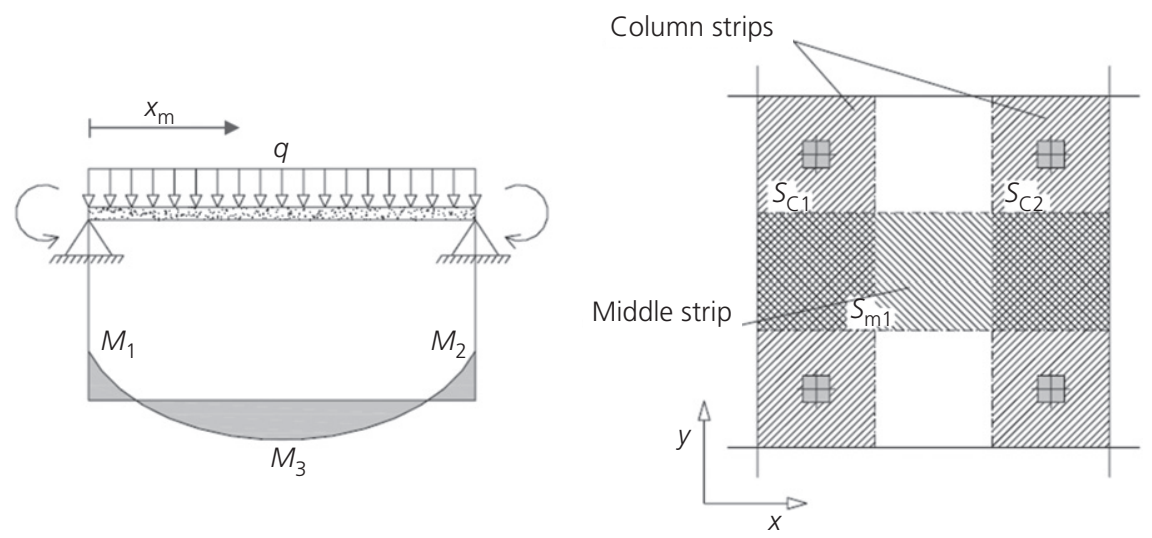

Figure 2. Structural discretisation for application of equivalent frame method. Loaded strip and bending moments (left) and column/middle strip plan (right)

dealing with a simplified method, this study adopted the equivalent frame method used by Calderón et al. (2011) in their study (see Figure 2).

Scanlon and Murray (1982) first proposed calculating vertical displacements by this method. In this work, the method involves determining the necessary bending moments of the column and middle strips and then determining the maximum deformation of each strip (column and middle) by applying the elastic beam equation according to the following expression:

14.

$$
\begin{aligned}
\Delta_{\max , \mathrm{s}}= & \frac{q x_{\mathrm{m}}}{24 E I}\left(x_{\mathrm{m}}^{3}-2 L x_{\mathrm{m}}^{2}+L^{3}\right)-\frac{M_{1} x_{\mathrm{m}}}{6 E I}\left(L-x_{\mathrm{m}}\right) \\
& \times\left[1+\frac{L-x_{\mathrm{m}}}{L}+\frac{M_{2}}{M_{1}}\left(1+\frac{x_{\mathrm{m}}}{L}\right)\right]
\end{aligned}
$$

where $q$ is the unitary load fraction assigned to each strip (column or middle), $x_{\mathrm{m}}$ is the point of maximum deformation of a strip, $L$ is the inter-column distance, $E$ is the time-dependent elasticity modulus of the concrete, $I$ is the moment of inertia of the strip under study, and $M_{1}$ and $M_{2}$ are the negative bending moments in the strip supports. The evolution of the elasticity modulus with time was estimated by the maturity technique described in detail in Alvarado (2009) and applied by Waller et al. (2004), Adam et al. (2007), Gasch (2012) and Buitrago et al. (2015). Additionally, the stiffness matrix method was considered to calculate the necessary $M_{1}$ and $M_{2}$ moments.

After calculating the maximum deformation of each strip, the maximum deformation of the analysed span in directions $x$ and $y$ is given by the maximum deformation of the column strip plus the maximum deformation of the middle strip, according to the following expressions

15. $\Delta_{\max , y}=\frac{\Delta_{\max , \mathrm{Sc} 1}+\Delta_{\max , \mathrm{Sc} 2}}{2}+\Delta_{\max , \mathrm{Sm} 1}$
16. $\Delta_{\max , x}=\frac{\Delta_{\max , \mathrm{Sc} 3}+\Delta_{\max , \mathrm{Sc} 4}}{2}+\Delta_{\max , \mathrm{Sm} 2}$

The maximum deformation of the span analysed is taken to be the mean of the maximum deformations calculated in directions $x$ and $y$

17. $k_{j, \max }=\frac{\Delta_{\max , y}+\Delta_{\max , x}}{2}$

\subsection{Calculation process}

The process followed to calculate maximum load in each construction phase is as follows.

- First, the maximum deformations under a unitary load $\left(k_{j, \max }\right)$ are obtained. To do this it is necessary to:

o apply the maturity method to determine the evolution of the concrete elasticity modulus $(E)$ of each slab in the construction phase under study

o apply the stiffness matrix method to calculate the necessary bending moments considering the buildings according to the conditions in each construction phase

o apply the equivalent frame method to calculate the maximum displacement of slabs under a unitary load.

- Shore deformation at the maximum slab deformation point $\left(k_{\mathrm{sh}, j, \mathrm{max}}\right)$ is then obtained.

- The next step consists of obtaining the load ratios between consecutively shored floors $(\alpha)$.

- Finally, the increased load on slabs $\left(Q_{j, \max }\right)$ is obtained. This increase is added to the history of the load increases of the previous construction phases, since the method allows cumulative loads. After obtaining the loads on slabs, the loads on the shores are obtained by equilibrium. 
After performing the above steps, equilibrium conditions are established between slabs and shores at the maximum slab deformation point, and the maximum load on the shores of each floor is obtained for all construction phases.

\section{Results and validation}

\subsection{Description of the test building}

The building used for the study was the one studied by Alvarado (2009), Alvarado et al. (2009) and Buitrago et al. (2015), consisting of three $0 \cdot 25 \mathrm{~m}$ thick reinforced concrete floor slabs, $2.75 \mathrm{~m}$ inter-floor height and an inter-column distance of $6.00 \mathrm{~m}$. Figure 3 shows a view of the building under construction and a scheme of its geometric definition.

The building was fitted with test instrumentation (Alvarado, 2009; Alvarado et al., 2009) and analysed by finite-element method (FEM) and simplified calculation methods in terms of mean loads (Alvarado, 2009; Alvarado et al., 2010; Buitrago et al., 2015; Calderón et al., 2011). The maximum loads on the shores in each construction phase were determined from these recordings and results, which were also used to validate the simplified calculation procedure for maximum loads proposed in the present paper.

\subsection{Validation}

Table 1 gives the maximum loads on shores calculated for each floor of the building in each construction phase $\left(S_{\max , \mathrm{NSP}}\right)$. In order to verify the proposed maximum load calculation procedure, these maximum loads were compared with the experimental results $\left(S_{\max , \text { Exp }}\right)$ and the FEM results $\left(S_{\max , \text { FEM }}\right)$. The ratios $S_{\max , \text { Exp }} / \mathrm{S}_{\max , \text { NSP }}$ and $S_{\max , \text { FEM }} / \mathrm{S}_{\max , \text { NSP }}$, which measure the goodness of fit of each calculated maximum load with respect to the experimental measurements and the FEM results, respectively, were also considered. Finally, the mean and standard deviation of the calculated ratios and total error were obtained. Total error was defined as the sum of the errors in absolute values of the calculated maximum loads in relation to the experimental measurements and the FEM results.

In Table 1 it can be seen that, in general, there is a better fit with the FEM results than with the experimental measurements. As Alvarado (2009) has pointed out, the experimental loads on shores are greatly affected by the way they are manipulated by the building workers, who do not usually operate in line with any strict procedures, so that it is reasonable to expect that the calculated maximum loads are closer to the FEM calculations. The FEM simulation was calibrated and verified by Alvarado (2009).

In the fit obtained with the FEM calculations, the mean ratio was 1.03 with a standard deviation of 0.13 and a total error of $4.83 \mathrm{kN}$, which implies that the mean error of each calculation was $0.44 \mathrm{kN}$ and the maximum was $0.94 \mathrm{kN}$. This maximum error of only $0.94 \mathrm{kN}$ appears in the striking of level 1 , which

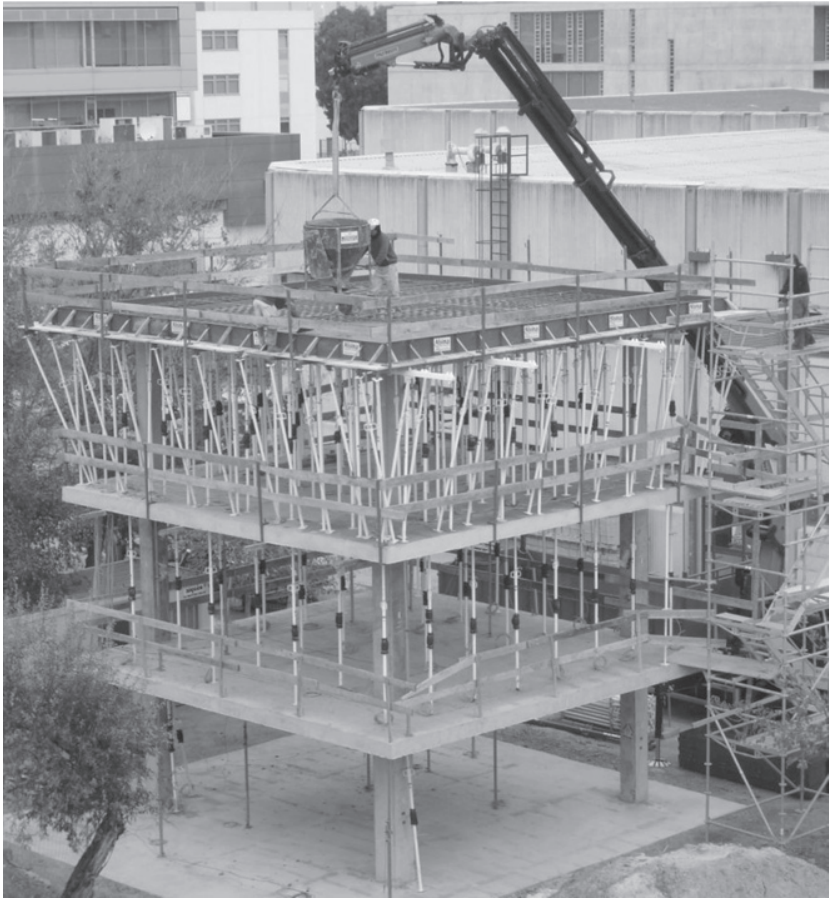

(a)

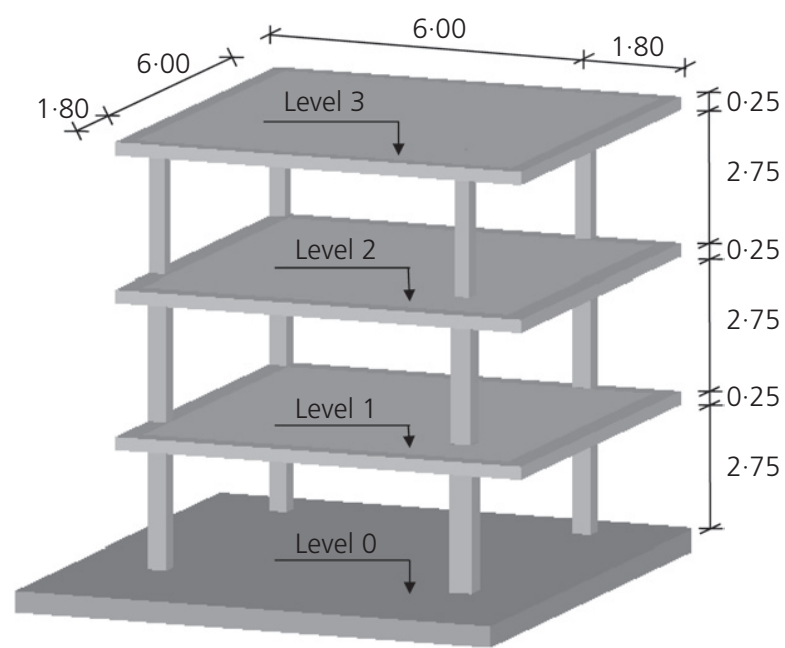

(b)

Figure 3. Building analysed: (a) view of building under construction; (b) three-dimensional scheme. All dimensions in $\mathrm{m}$

is a construction phase with relatively light loads. Also, it is precisely in this phase that the shore with the highest load is not necessarily located at the point of highest slab deformation.

A graph showing the evolution of the maximum loads on each floor by comparing the results of the simplified method (continuous lines) with the FEM results (broken lines) can be seen in Figure 4, in which the maximum loads of the different levels are given in different colours. As commented above for the results of Table 1, it can be seen that, on all the levels, the 


\begin{tabular}{|c|c|c|c|c|c|c|}
\hline Stage of construction & Level & 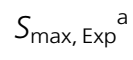 & $S_{\max , \text { FEM }^{a}}$ & $S_{\max , \text { NSP }}$ & $S_{\max , \operatorname{Exp}} / S_{\max , \text { NSP }}$ & $S_{\max , \text { FEM }} / S_{\max , \text { NSP }}$ \\
\hline Casting level 1 & 1 & $7 \cdot 71$ & 6.85 & $6 \cdot 77$ & $1 \cdot 14$ & 1.01 \\
\hline Clearing level 1 & 1 & $8 \cdot 43$ & 10.91 & $10 \cdot 60$ & 0.80 & 1.03 \\
\hline \multirow{2}{*}{ Casting level 2} & 2 & 8.63 & $6 \cdot 85$ & $6 \cdot 77$ & $1 \cdot 27$ & 1.01 \\
\hline & 1 & $14 \cdot 57$ & $21 \cdot 37$ & $20 \cdot 72$ & $0 \cdot 70$ & 1.03 \\
\hline \multirow[t]{2}{*}{ Clearing level 2} & 2 & 8.08 & $9 \cdot 25$ & 9.03 & 0.89 & 1.02 \\
\hline & 1 & $11 \cdot 30$ & 17.92 & $17 \cdot 24$ & 0.66 & 1.04 \\
\hline Striking level 1 & 2 & $4 \cdot 88$ & $3 \cdot 32$ & $2 \cdot 38$ & 2.05 & $1 \cdot 39$ \\
\hline \multirow[t]{2}{*}{ Casting level 3} & 3 & $8 \cdot 84$ & 6.85 & $6 \cdot 77$ & $1 \cdot 31$ & 1.01 \\
\hline & 2 & $8 \cdot 23$ & 7.64 & 8.57 & 0.96 & 0.89 \\
\hline \multirow[t]{2}{*}{ Clearing level 3} & 3 & $11 \cdot 27$ & 8.33 & 8.42 & $1 \cdot 34$ & 0.99 \\
\hline & 2 & $7 \cdot 28$ & 5.41 & $6 \cdot 18$ & $1 \cdot 18$ & 0.88 \\
\hline Mean & & & & & $1 \cdot 12$ & 1.03 \\
\hline Standard deviation & & & & & 0.39 & 0.13 \\
\hline Total error: kN & & & & & $26 \cdot 87$ & 4.83 \\
\hline
\end{tabular}

a Based on Alvarado (2009), Alvarado et al. (2009, 2010) and Buitrago et al. (2015).

Table 1. Maximum loads on shores $(\mathrm{kN})$ and proposed method verification

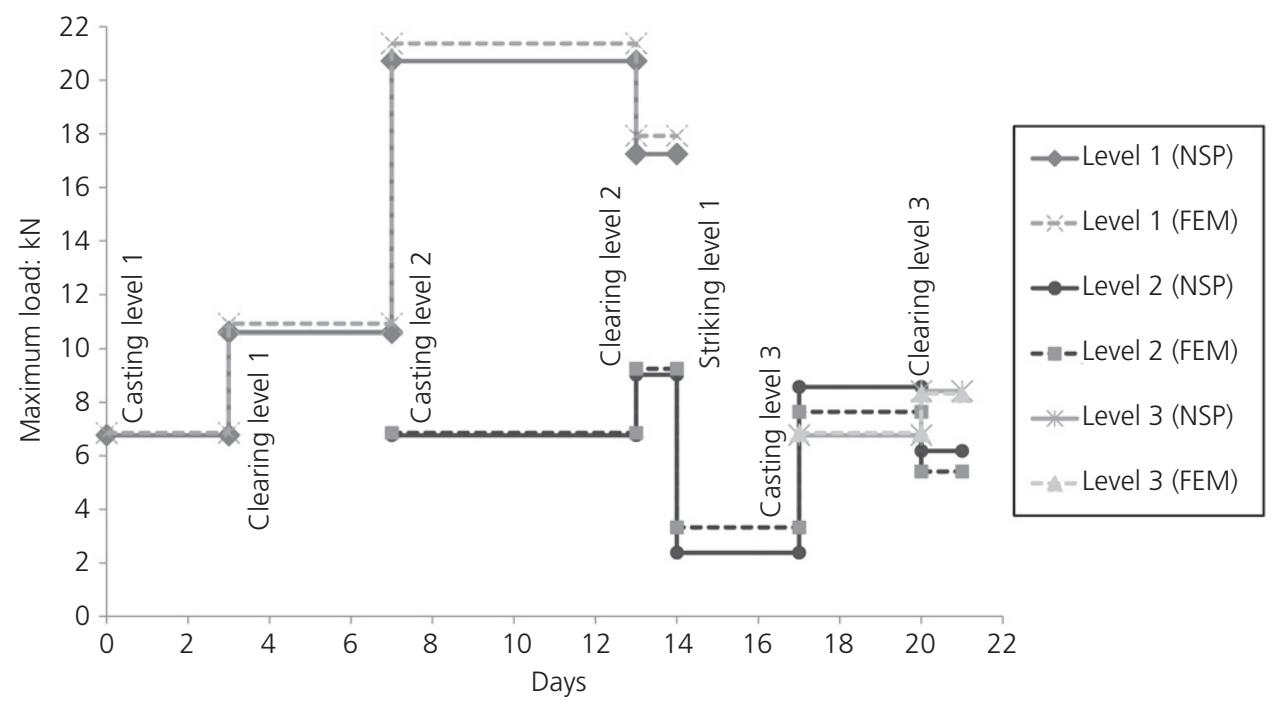

Figure 4. Evolution of maximum loads on all floors according to simplified maximum load calculation method (NSP) and FEM

loads calculated by the simplified method predict the FEM results with a good degree of accuracy.

Another point of interest is that, as the shores used on the lower floors have to be reused on the upper floors, the maximum load they have to bear (option 1) is taken as the shore design load. In this case the simplified method predicts a maximum load of $20.72 \mathrm{kN}$, which is close to $21.37 \mathrm{kN}$ calculated by the FEM method. However, it is also possible to set the maximum load that the shores have to withstand on individual floors as the design load (option 2). In this case, the loads given by the simplified method also show a good fit with the FEM results for the different levels: $20 \cdot 72 \mathrm{kN}$ as opposed to $21.37 \mathrm{kN}$ on level $1,9.03 \mathrm{kN}$ as opposed to $9.25 \mathrm{kN}$ on level 2, and $8.42 \mathrm{kN}$ as opposed to $8.33 \mathrm{kN}$ on level 3 . A summary of both options for setting the shore design load is given in Table 2, in which it can also be seen that the simplified maximum load calculation method (NSP) shows a good 
Level

NSP: kN

FEM: kN

\section{Option 1}

$$
\text { - }
$$

Option 2

1

2

$9 \cdot 03$

Table 2. Shore design loads ( $\mathrm{kN}$ ) according to the different options considered

fit with the FEM calculations. The proposed calculation method can therefore be said to ensure the correct choice of the type of shore to use for both option 1 and option 2 .

Finally, it is fundamental to highlight the importance of considering the calculation of maximum loads on shores instead of only considering load transmission in terms of mean loads. Using mean loads in the analysis is only valid for knowing the slab loads and checking the slab resistances. However, maximum load must be considered when calculating the shore design load. In fact, if in Figure 5 the maximum shore load obtained in this work is compared with the mean shore load obtained by FEM (Alvarado, 2009; Calderón et al., 2011), it is obvious that failing to consider maximum load leads to unsafe shoring system designs on all levels.

\section{Conclusions}

This paper describes a simplified method of calculating maximum loads on shores during each phase of the construction of buildings with in situ casting. This proposed method provides the design load of the shores used in the building, since these are selected according to the maximum load they must withstand

- avoids the safety problems that could arise from selecting the wrong type of shore; actually, designing shoring based on mean loads underestimates the loads in shores

- showed a good fit in general and was verified by experimental measurements and FEM calculations included in previous publications by the present authors. When compared to the experimental measurements, the calculations performed for the different operations show the correct evolution of the recorded maximum loads, in spite of the influence of the rough handling of shores by the building workers. The comparison with the FEM calculations also shows a good fit with mean errors of $0.44 \mathrm{kN}$ in each calculation of the maximum load. Furthermore, the maximum load obtained from the simplified method is $20.72 \mathrm{kN}$, which is very close to the value $21.37 \mathrm{kN}$ obtained from an advanced FEM. The largest errors were detected during the striking phase, in which the highest loaded shore was not necessarily found to be at the point of highest slab deformation. In addition, in this construction phase the loads are comparatively light and below the shore design load.

The proposed simplified procedure therefore achieves a good degree of fit and can be considered as useful to both researchers and practitioners, who are routinely faced with this problem in their day-to-day work. It also implies an important transfer of technology to the industry, as it takes the form of a simple tool that comes close to the response obtained from complex calculation methods.

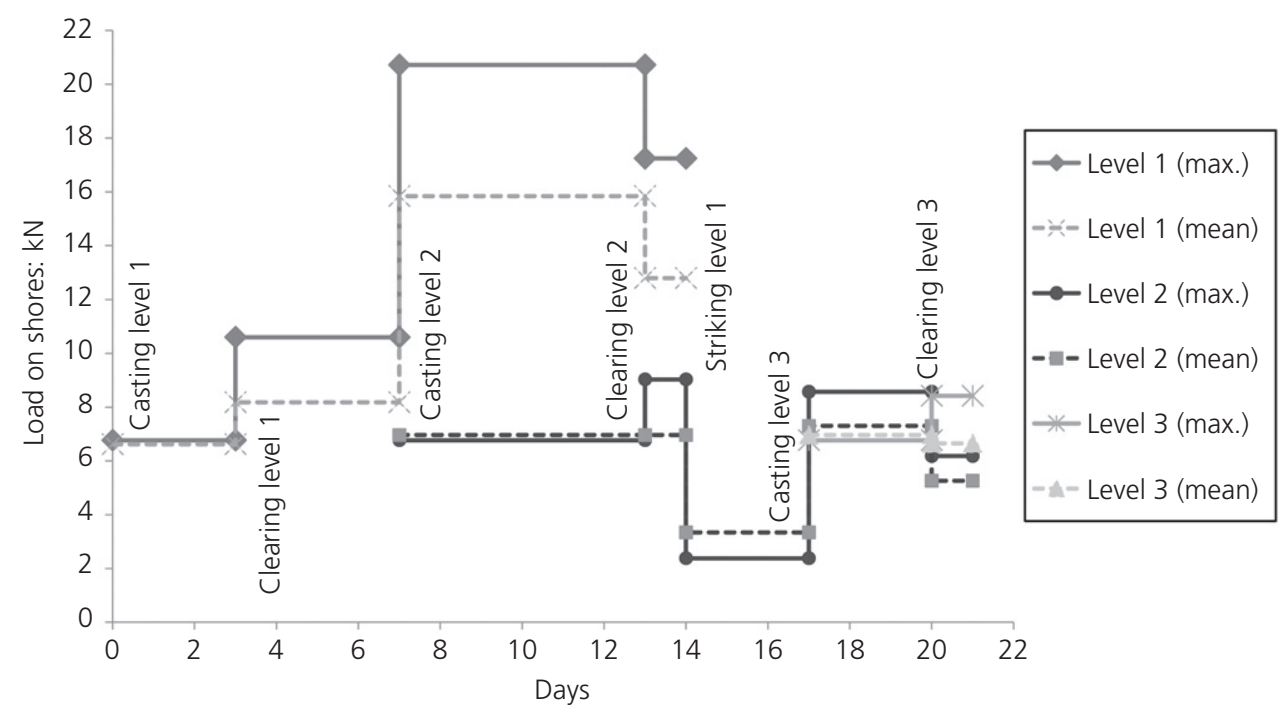

Figure 5. Comparison of mean and maximum loads on shores 


\section{Acknowledgements}

The authors would like to express their gratitude to the Spanish Ministry of Education, Culture and Sport for funding received under the FPU Program (FPU13/02466) and also to the Generalitat Valenciana (GV/2015/063).

\section{REFERENCES}

Adam JM, Pallarés FJ, Calderón PA and Payá IJ (2007) A study of the conditions of use of a new safety system for the building industry. Engineering Structures 29(8): 1690-1697.

Alvarado YA (2009) Estudio Experimental y Numérico de la Construcción de Forjados Hormigonados in Situ Mediante Procesos de Cimbrado, Clareado y Descimbrado de Plantas Consecutivas. $\mathrm{PhD}$ thesis, Universidad Politécnica de Valencia, Valencia, Spain. See http://hdl.handle.net/10251/ 7285 (accessed 23/08/2015) (in Spanish).

Alvarado YA, Calderón PA, Adam JM et al. (2009) An experimental study into the evolution of loads on shores and slabs during construction of multistory buildings using partial striking. Engineering Structures 31(9): 2132-2140.

Alvarado YA, Calderón PA, Gasch I and Adam JM (2010) A numerical study into the evolution of loads on shores and slabs during construction of multi-storey buildings. Comparison of partial striking with other techniques. Engineering Structures 32(10): 3093-3102.

Buitrago M, Alvarado YA, Adam JM et al. (2015) Improving construction processes of concrete building structures using load limiters on shores. Engineering Structures 100(15): 104-115.

Calderón PA, Alvarado YA and Adam JM (2011) A new simplified procedure to estimate loads on slabs and shoring during the construction of multistorey buildings. Engineering Structures 33(11): 1565-1575.

Duan MZ and Chen WF (1995) Improved Simplified Method for Slab and Shore Load Analysis During Construction. Purdue University, West Lafayette, IN, USA, Project report CE-STR-95-21.
Epaarachchi D, Stewart M and Rosowsky D (2002) Structural reliability of multistory buildings during construction. Journal of Structural Engineering 128(2): 205-213.

Fang DP, Zhu HY, Geng CD and Liu XL (2001) On-site measurements of structural characteristics of reinforced concrete buildings during construction. ACI Structural Journal 98(2): 157-163.

Gasch I (2012) Estudio de la Evolución de Cargas en Forjados y Estructuras Auxiliares de Apuntalamiento Durante la Construcción de Edificios de Hormigón in situ Mediante Procesos de Cimbrado, Clareado y Descimbrado de Plantas Consecutivas. $\mathrm{PhD}$ thesis, Universidad Politécnica de Valencia, Valencia, Spain. See http://hdl.handle.net/10251/ 15407 (accessed 23/08/2015) (in Spanish).

Gasch I, Alvarado YA, Calderón PA and Torres B (2013) Load transmission between slabs and shores in a building with cast-in-place girderless hollow floor slab using partial striking. Informes de la Construcción 65(530): 195-202.

Gasch I, Alvarado YA, Calderón PA and Ivorra S (2014) Construction loads using a shoring-clearing-striking process. Proceedings of the Institution of Civil Engineers Structures and Buildings 167(4): 217-229, http://dx.doi.org/ 10.1680/stbu.12.00006.

Grundy P and Kabaila A (1963) Construction loads on slabs with shored formwork in multistorey buildings. $A C I$ Journal Proceedings 60(12): 1729-1738.

Kaminetzky D (1991) Design and Construction Failures: Lessons from Forensic Investigations. MacGraw-Hill, New York, NY, USA.

Kaminetzky D and Stivaros P (1994) Early-age concrete: construction loads, behavior, and failures. Concrete International 16(1): 58-63.

Scanlon A and Murray DB (1982) Practical calculation of two-way slab deflection. Concrete International: Design and Construction 4(11): 43-50.

Waller V, d'Aloïa L, Cussigh F and Lecrux S (2004) Using the maturity method in concrete cracking control at early ages. Cement and Concrete Composites 26(5): 589-599.

\section{WHAT DO YOU THINK?}

To discuss this paper, please email up to 500 words to the editor at journals@ice.org.uk. Your contribution will be forwarded to the author(s) for a reply and, if considered appropriate by the editorial panel, will be published as discussion in a future issue of the journal.

Proceedings journals rely entirely on contributions sent in by civil engineering professionals, academics and students. Papers should be 2000-5000 words long (briefing papers should be 1000-2000 words long), with adequate illustrations and references. You can submit your paper online via www.icevirtuallibrary.com/content/journals, where you will also find detailed author guidelines. 